\title{
Optimising the management of pulmonary arterial hypertension patients: emergency
} \section{treatments}

\author{
M. Delcroix* and R. Naeije ${ }^{\#}$
}

ABSTRACT: Pulmonary arterial hypertension (PAH) is a rare and potentially fatal disease whose management is usually restricted to a few specialised centres. As patients do not necessarily live in the neighbourhood of these centres, daily care and emergencies have to be delegated to first and second lines. Treatment guidelines do not usually provide recommendations for acute emergency situations as evidence is scarce. This short review provides a description of our therapeutic protocols based on available data.

A model of transmural organisation of care for PAH patients, currently applied in Belgium, is described. Thereafter, based on an analysis of the reasons of death in the PAH population, a review of the main emergencies is provided. Cardiac arrest and resuscitation, decompensated right heart failure, respiratory failure, arrhythmia, pericardial effusion, haemoptysis, surgery and drug-related adverse events will be discussed successively.

Case reports showing the precariousness of PAH patients will enforce our thesis of the need for optimal patient management organisation.

KEYWORDS: Emergencies, organisation of care, pulmonary arterial hypertension

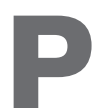

ulmonary arterial hypertension $(\mathrm{PAH})$ is a rare and potentially fatal disease which is either idiopathic, heritable or associated with other conditions, such as congenital heart diseases, connective tissue diseases, HIV infection, drug and toxin exposition, portal hypertension, schistosomiasis and chronic haemolytic anaemia [1].

With a prevalence of $30-50$ cases per million inhabitants [2, 3], PAH is considered as an orphan disease (less than 1 case per 2,000 inhabitants). Therefore, care of these patients is usually restricted to a few specialised centres. However, since patients do not necessarily live in the neighbourhood of these centres, daily care and emergencies have to be delegated to first and second lines. However, because of the lack of medical evidence, treatment guidelines usually do not provide recommendations regarding these potentially life-threatening problems $[4,5]$.

In the present review, we give some indications to the caregivers facing acute medical problems in the $\mathrm{PAH}$ population. Furthermore, transmural programmes have to be elaborated with the following aims: 1) ensuring uniformity of the medical approach; 2) definition of competence levels; and 3) network organisation between medical partners. The ultimate goal of these programmes is to prevent acute death and offer similar chances to every PAH patient with optimal input of all partners.

\section{ORGANISING PATIENT MANAGEMENT}

The model of the transmural programme we promote in Belgium is illustrated in figure 1. As expected, the first line is assumed by the general practitioner who has detected the first symptoms of the disease, and is in charge of the fine tuning of oral anticoagulants and diuretics, and of the control of the liver function tests in case of therapy with an endothelin receptor antagonist (ERA). The second level is the local specialist who has diagnosed pulmonary hypertension. Because of local accessibility, he will manage some of the medical problems occurring during the course of disease. He will perform ECG and Holter monitoring in case of palpitations, will be responsible for oxygen prescription and reimbursement, and will care for emergency admissions. The third level can be assumed by competence centres.

\section{AFFILIATIONS}

*Dept of Pneumology, University Hospitals of Leuven, Katholieke Universiteit Leuven, Leuven, and \#Dept of Physiology, Free University of Brussels, Brussels, Belgium.

CORRESPONDENCE

M. Delcroix

Dept of Pneumology University Hospital Gasthuisberg Herestraat 49 3000 Leuven

Belgium

E-mail: marion.delcroix@

uzleuven.be

Received:

May 192010

Accepted after revision:

July 062010

PROVENANCE

Publication of this peer-reviewed article was supported by Pfizer, Ltd (principal sponsor, European Respiratory Review issue 117). 


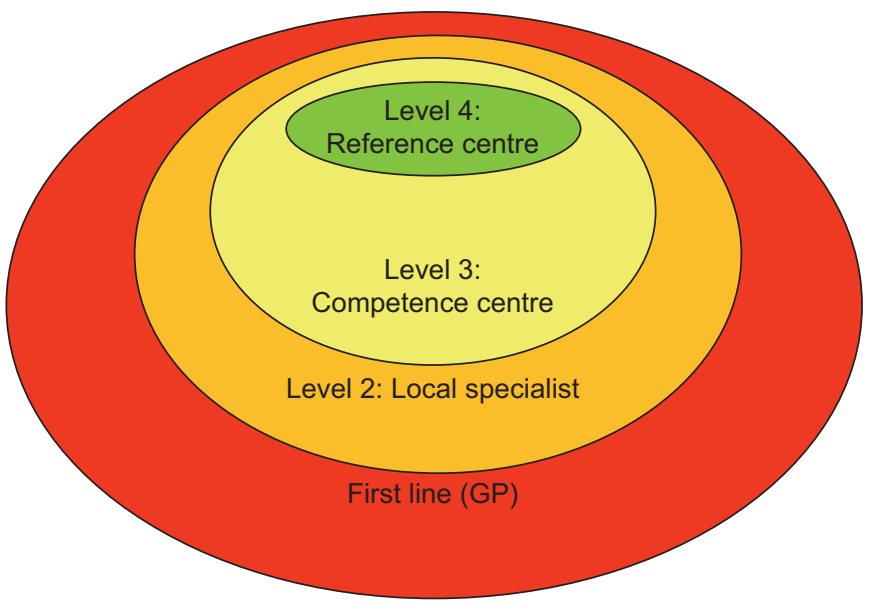

FIGURE 1. Model of transmural care programme for patients with pulmonary arterial hypertension. GP: general practitioner

These are large or university centres who are able to confirm the diagnosis of $\mathrm{PAH}$, are performing reversibility testing with nitric oxide (NO) (sometimes with epoprostenol), and are allowed to prescribe oral drugs (ERA and phosphodiesterase 5 inhibitors) alone or in combination. The fourth level is assumed by the reference centres, one for each linguistic community (Dutch and French). These offer all therapeutic approaches, including parenteral prostacyclines (PGI2), new drugs (in trials, compassionate use and early access programmes), atrial septostomy, (heart-)lung transplantation and pulmonary endarterectomy.

\section{CAUSES OF DEATH}

In the American National Institute of Health registry, 106 deaths were reported in a cohort of 194 patients with idiopathic PAH. 26\% were sudden death, $47 \%$ were due to right ventricular failure, and $27 \%$ were due to other causes (medication, surgery, pneumonia $7 \%$, and cerebrovascular accident). When we revisited the UZ Leuven, Belgium, database, we found 99 deaths in a cohort of $316 \mathrm{PAH}$ patients. The causes of death are presented in table 1.

From these types of reports we can obtain a picture of the most frequent emergencies faced during the course of $\mathrm{PAH}$, namely cardiac arrest and resuscitation, right ventricular failure, $\mathrm{PAH}$ exacerbation, respiratory failure, arrhythmia, pericardial effusion, haemoptysis, surgery and drug-related adverse events.

\section{MEDICAL EMERGENCIES}

\section{Cardiac arrest and resuscitation}

Cardiopulmonary resuscitation (CPR) in patients with PAH has very poor outcome, as illustrated in the retrospective survey by HOEPER et al. [6]. In a population of 3,130 patients with PAH treated between 1997 and 2000 in 17 reference centres in Europe and the USA, 513 patients had a circulatory arrest. CPR was attempted in 132 (26\%) of these patients: $96 \%$ in hospitalised patients, $74 \%$ in intensive care units. Resuscitation efforts were primarily unsuccessful in 104 patients (79\%). Only eight patients $(6 \%)$ survived for $>90$ days. Except for one, all long-term survivors had identifiable causes of circulatory arrest that were rapidly reversible.

\begin{tabular}{lcc} 
TABLE 1 Causes of death in 99 patients with pulmonary \\
& arterial hypertension in UZ Leuven, Belgium \\
Sudden death & 18 \\
Pulmonary hypertension crisis & 1 \\
Respiratory failure & 2 \\
Pneumonia & 3 \\
Massive haemoptysis & 1 \\
Liver failure & 3 \\
Atrial septostomy & 1 \\
Acute pulmonary embolism & 1 \\
Ischaemic colitis & 1 \\
Medication withdrawal & 1 \\
Right ventricular failure & 32 \\
Hyperthyroidism & 1 \\
Sepsis & 8 \\
Bleeding (other) & 2 \\
Intracranial bleeding & 2 \\
Liver transplantation & 2 \\
Anaesthesia & 1 \\
Cancer & 2 \\
Myocardial infarction & 3 \\
Unknown & 1 \\
\hline & 15 \\
\hline
\end{tabular}

Facing this poor outcome it makes sense to say that no resuscitation should be undertaken in patients with a combination of: 1) New York Heart Association (NYHA) class IV; 2) intractable right heart failure with more than two hospital admissions over the past 6 months; 3) maximal PAHspecific drug therapy (including parenteral PGI2); 4) atrial septostomy if indicated; 5) lung transplantation not indicated; and 6) persistent intolerable suffering from dyspnoea, anxiety and pain.

\section{Heart failure in PAH}

$\mathrm{PAH}$ is characterised by remodelling of the precapillary pulmonary arteries. There is intimal fibrosis, medial hypertrophy, adventitial proliferation and, in a proportion of patients, fibrinoid necrosis and/or plexiform lesions. The effect of progressive vessel narrowing is to increase pulmonary vascular resistance and, thereby, pulmonary arterial pressure. At a certain point, the heart will fail and cardiac output will decrease. Echocardiographic examination reveals right ventricle dilatation and hypokinesis, interventricular septal flattening and paradoxic motion, and tricuspid valve regurgitation (fig. 2). Right ventricular failure also generates left ventricular dysfunction and global heart failure. There is decreased filling of the left ventricle because of the decreased amount of blood flow passing through the lungs (decreased preload) and because of decreased left ventricle compliance caused by competition for space within the pericardium (ventricular interdependence; fig. 2). There is also a decreased coronary perfusion related to increased right ventricle pressure with low systemic perfusion pressure. This will cause a rapid decrease in patient exercise capacity, clinical signs of heart failure (jugular distension, hepatomegaly, oedema and ascites) and angina pectoris.

Acute episodes of heart failure, sometimes called "PAH exacerbations", have been recently described by SZTRYMF 


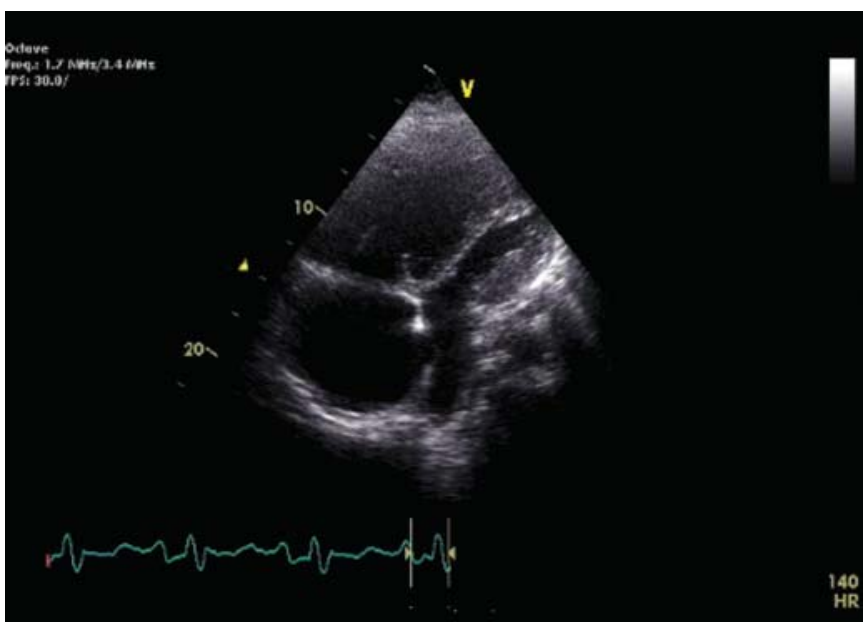

FIGURE 2. Global heart failure in pulmonary arterial hypertension.

et al. [7] from the French reference centre. The authors prospectively studied 46 consecutive patients with acute right ventricular failure requiring intensive care unit (ICU) hospitalisation and catecholamine therapy. 52\% had idiopathic PAH, $33 \%$ associated PAH, 15\% distal chronic thromboembolic pulmonary hypertension (CTEPH), and 50\% were treated with intravenous epoprostenol. Mortality reached $41 \%$. Predictors of mortality at admission were high brain natriuretic peptide (BNP) plasma levels (median (range) 1,415 (449-3,550) in nonsurvivors versus $628(87-1,460) \mathrm{pg} \cdot \mathrm{mL}^{-1}$ in survivors; $\mathrm{p}=0.0007)$, high $\mathrm{C}$-reactive protein (CRP) $(40$ (0-270) versus $\left.12(0-200) \mathrm{mg} \cdot \mathrm{L}^{-1} ; \mathrm{p}=0.01\right)$, and high creatinine (112 (42-144) versus $\left.95(82-151) \mu \mathrm{mol} \cdot \mathrm{L}^{-1} ; \mathrm{p}=0.04\right)$. Predictors of mortality during hospitalisation were BNP, CRP, creatinine, sodium, systemic blood pressure and dobutamine dose (all $\mathrm{p}<0.05$ ). Demonstration of an infection during ICU stay was also associated with a worse prognosis.

A similar paper from Poland described 60 episodes of decompensated right ventricular failure in $37 \mathrm{PAH}$ or CTEPH patients [8]. Half of these episodes were precipitated by infection $(27 \%)$, drug noncompliance $(20 \%)$ or acute pulmonary embolism (3\%). In-hospital mortality was $32 \%$. Predictors of mortality were the clinical aspect of heart failure (with $48 \%$ death in the warm-wet type and $100 \%$ in the more rare cold-dry type), NYHA functional class, transaminases and dopamine dose (with a relative risk of 2.0 per $\mu \mathrm{g} \cdot \mathrm{kg}^{-1} \cdot \mathrm{min}^{-1}$ ). Rescue therapy with iloprost and treprostinil was a predictor of survival (relative risk of 0.09). Triggering factors for acute right heart failure are summarised in table 2.

Only a few papers have dealt with the management of PAH patients in the ICU. The review by ZAMANIAN et al. [9] proposed a quite comprehensive treatment algorithm (fig. 3). Treatment of right ventricular failure includes: 1) fluid management in order obtain optimal preload and cardiac output, as both hypovolaemia and hypervolaemia are detrimental (fig. 4); 2) control of arrhythmias, with maintenance of sinus rhythm and atrioventricular synchrony; and 3) inotropic support; and 4) use of selective pulmonary vasodilators.

The syndrome of heart failure, left as well as right, is one of cardiorenal failure, in which concomitant cardiac and renal
TABLE 2 Triggering factors for right heart failure

PAH-specific therapy withdrawal

Diuretics withdrawal

Infection (septicaemia, pneumonia, etc.)

Cardiac arrhythmia

Acute pulmonary embolism

Hyperthyroidism

Pregnancy

PAH: pulmonary arterial hypertension.

dysfunctions exist, with each accelerating the progression of the other. The pathophysiology of the cardiorenal syndrome is poorly understood and, most likely, involves interrelated haemodynamic and neurohormonal mechanisms [11]. Venous congestion has recently been shown as the most important haemodynamic factor driving worsening renal function in decompensated patients with advanced heart failure [12]. It should be targeted by aggressive diuresis. Loop diuretics are most efficient, even in patients with poor renal function. Fractionated doses and combination with other diuretics is recommended. Because of decreased absorption of oral drugs due to hypoperfusion and congestion intravenous use can be needed and is better in drip than in bolus.

In $\mathrm{PAH}$, inotropic support is usually provided with dobutamine, a $\beta_{1}$-agonist, administered at a low dose $\left(5 \mu \mathrm{g} \cdot \mathrm{kg}^{-1} \cdot \mathrm{min}^{-1}\right)$, which has been shown to normalise right ventriculo-arterial coupling and cardiac output and to decrease pulmonary vascular resistance in an acute pulmonary hypertensive animal model [13]. Dopamine, an $\alpha$-, $\beta$ - and dopaminergic agonist, has similar haemodynamic effects, and may allow for a better preservation of systemic blood pressure. Norepinephrine, an $\alpha_{1}$ - and $\beta_{1}$-agonist, improves blood pressure and improves, but does not normalise, right ventriculo-arterial coupling and cardiac output when administered at a dose of $0.1-$ $0.5 \mu \mathrm{g} \cdot \mathrm{kg}^{-1} \cdot \mathrm{min}^{-1}$ [13]. Milrinone, a phosphodiesterase 3 inhibitor, improves right ventricular function after cardiac surgery with hypotension as a side-effect. No data are available in patients with $\mathrm{PAH}$, but animal data suggest additive pulmonary vasodilation when combined with inhaled $\mathrm{NO}$ or sildenafil $[14,15]$. Digoxine, at a dose of $1 \mathrm{mg}$, may induce a small increase in cardiac output [16]. Levosimodan, a calcium sensitiser, increases cardiac output without increase in oxygen consumption and decreases pulmonary vascular resistance, and as such shows promise for the improvement of right ventriculo-arterial coupling $[17,18]$. Vasopressin, a weak nonadrenergic systemic vasopressor, may increase pulmonary vascular resistance at high doses and is, therefore, not recommended [19].

Pulmonary vasodilators are seldom needed in acute right heart failure. Inhaled NO has been most widely used because of its selective action on the pulmonary circulation [20]. The occurrence of rebound pulmonary hypertension when administration is interrupted has limited its use [21]. The inhaled prostacyclin analogue iloprost is a valuable alternative, inducing even more pronounced haemodynamic improvement acutely [22]. Upgrading PAH-specific therapy, with double or even triple combined therapy, is usually performed after an 


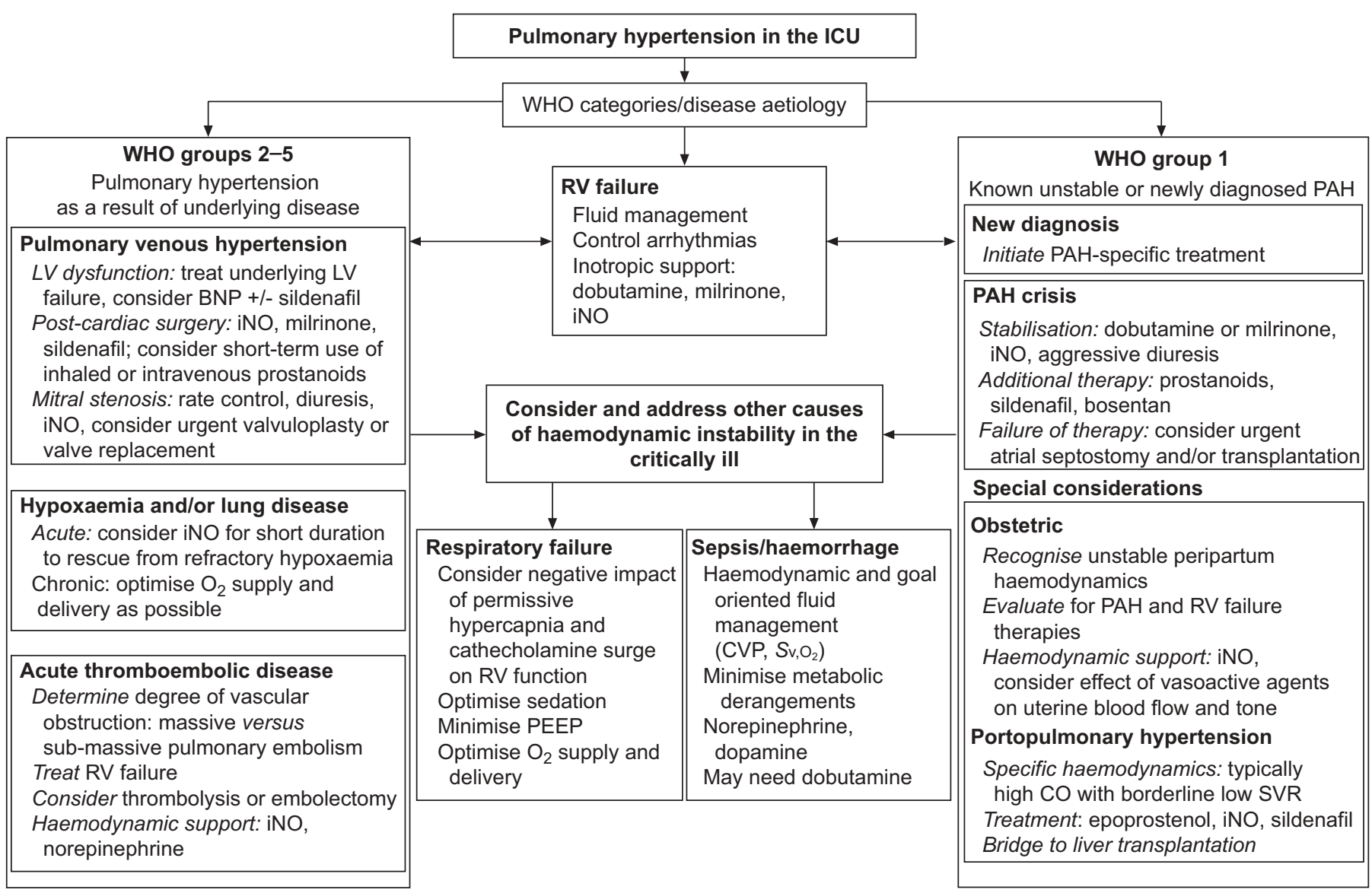

FIGURE 3. Management algorithm for patients with pulmonary hypertension in the intensive care unit (ICU). WHO: World Health Organization; RV: right ventricular; LV: left ventricular; BNP: brain natriuretic peptide; iNO: inhaled nitric oxide; PEEP: positive end-expiratory pressure; CVP: central venous pressure; $\mathrm{Sv}_{\mathrm{O}} \mathrm{O}_{2}$ : mixed venous oxygen saturation; PAH: pulmonary arterial hypertension; CO: cardiac output; SVR: systemic vascular resistance. Reproduced from [9] with permission from the publisher.

acute episode of right heart failure. Our practical approach for decompensated right heart failure is described in table 3.

\section{RESPIRATORY FAILURE}

In $\mathrm{PAH}$, severe hypoxaemia is essentially caused by a low mixed venous oxygenation in the presence of mildly altered ventilation-perfusion matching, and arterial carbon dioxide tension is low because of hyperventilation [23]. Shunt through a patent foramen ovale is an additional cause of hypoxaemia in patients with severe $\mathrm{PAH}$. Thus, $\mathrm{PAH}$ is not intrinsically a cause of respiratory failure. However, occasional patients present with shunting on atelectasis caused by compression of lung tissue by the dilated heart, pneumonia and, even more uncommonly, lung oedema on significant veno-occlusive disease. Additionally, compression of the main stem bronchi by dilated pulmonary arteries can mimic severe asthma [24].

When PAH patients require mechanical ventilation, because of concomitant lung disease as a cause of acute respiratory failure, or because of the need of a general anaesthesia for an intercurrent condition, it seems wise to advise an increase in the fraction of inspired oxygen to normalise arterial oxygen tension. Hypercapnia and hyperinflation should be avoided because of a concern about further increase in pulmonary vascular resistance [9]. Recent data from patients with acute respiratory distress syndrome show that both hypercapnia, induced by tidal volume reduction, and increase in positive end-expiratory pressure are associated with impaired right ventricular function [25]. Norepinephrine is used to maintain blood pressure. There are no data on noninvasive ventilation in $\mathrm{PAH}$ patients.

\section{ARRHYTHMIAS}

Malignant ventricular arrhythmias are rare in PAH patients. Only $8 \%$ of 132 witnessed cardiac arrests in the series reported by HOEPER et al. [6] were associated with ventricular fibrillation. In contrast, supraventricular tachyarrhythmias are quite frequent, with an incidence of $2.8 \%$ per year [26]. Atrial flutter and fibrillation are equally common and invariably associated with deterioration and right ventricular failure for which they are a cause or a consequence. Treatment of flutter is more successful than fibrillation and persistent atrial fibrillation is associated with 2-yr mortality $>80 \%$. Atrial fibrillation/flutter are poorly tolerated in PAH because of decreased ventricular compliance, which renders right ventricular filling dependent on the atrial contraction [27]. Treatment with beta-blockers is not recommended because of negative inotropy and possible pulmonary vasoconstriction [28]. Cordarone is the preferred drug but it may cause life-threatening thyrotoxicosis in the long term. Electrical cardioversion is used regularly and radiofrequency ablation has been performed. 

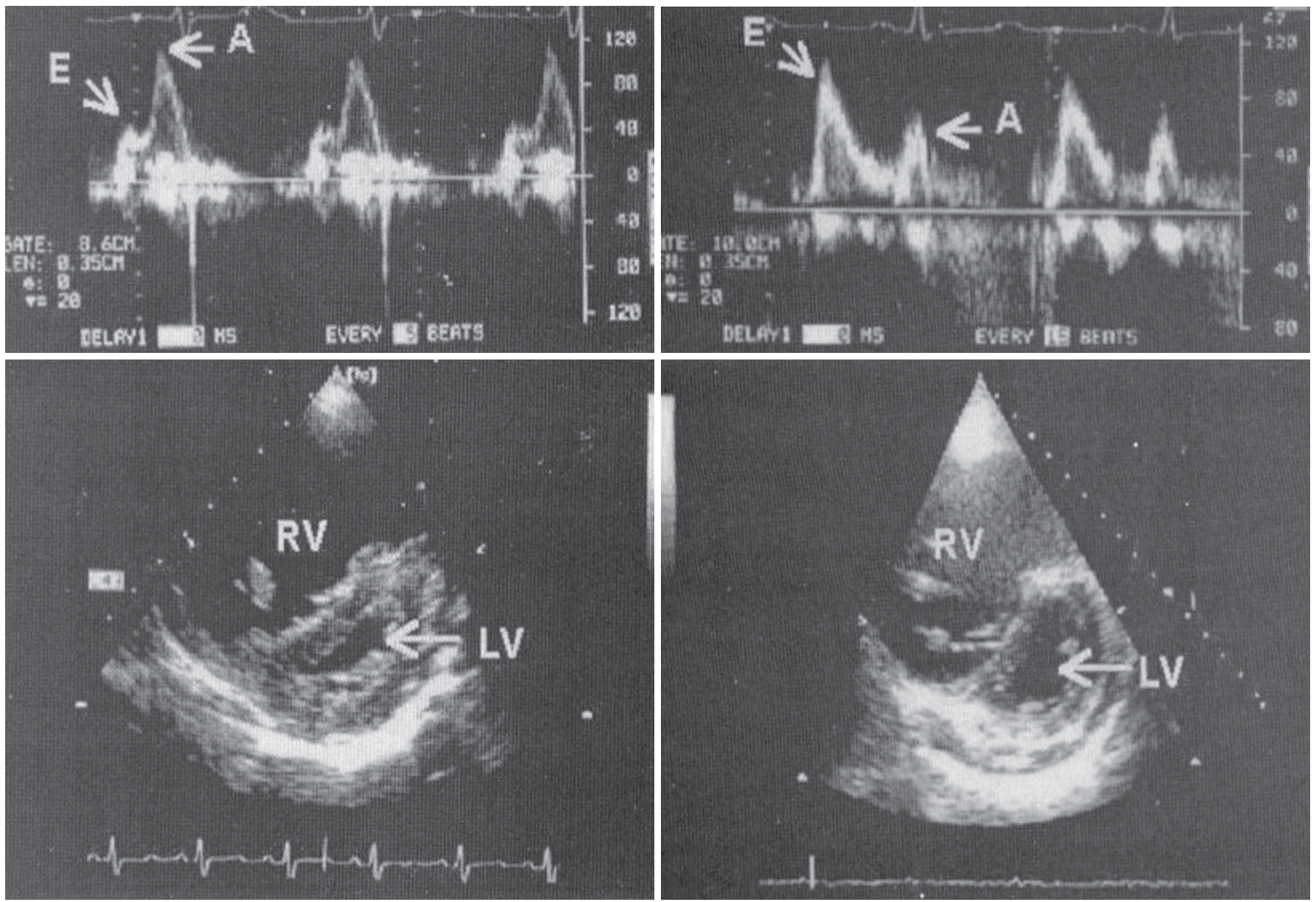

FIGURE 4. Effect of intravenous furosemide in a pulmonary arterial hypertension patient admitted with overt right heart failure documented by echo-Doppler of the heart. At base line (left panels), right ventricle is hugely dilated inducing left ventricle collapse and a restrictive mitral flow pattern with decreased E/A ratio. After acute diuresis (right panels), left ventricle can fill better and E/A ratio is restored. Reproduced from [10] with permission from the publisher

\begin{tabular}{l} 
TABLE 3 Proposed practical approach for right ventricular \\
failure \\
Diuretics \\
Slowly increased \\
Oral: bumetamide up to $10 \mathrm{mg}(\mathrm{b}$.i.d. or t.i.d.) \\
i.v. drip if necessary ( $1 \mathrm{mg}$ per $\mathrm{h})$ \\
Association with spironolactone $50-100 \mathrm{mg}$ and chlorthalidone $50 \mathrm{mg}$ \\
Switch from bumetamide to furosemide up to $600 \mathrm{mg}$ \\
Sodium and fluid restriction \\
Sometimes haemofiltration \\
Intermittent paracentesis for therapy-resistant ascites and pleural effusion \\
Inotropes \\
7-day course \\
Dobutamine $4-6 \mu \mathrm{g} \cdot \mathrm{kg}^{-1} \cdot \mathrm{min}^{-1}$ (peripheral administration is acceptable) \\
Low blood pressure: dopamine $4-6 \mu \mathrm{g} \cdot \mathrm{kg}^{-1} \cdot \mathrm{min}^{-1}$ \\
Heart rate $>110$ beats per min + digoxine $0.5 \mathrm{mg}^{i . v}$. \\
Vasodilators \\
Seldom needed \\
Inhaled NO $10-20 \mathrm{ppm}$ \\
Inhaled iloprost $150 \mu \mathrm{g}$ per day (every $2-3 \mathrm{~h}$ or even continuously) \\
\hline
\end{tabular}

\section{PERICARDIAL EFFUSION}

Tamponade is unusual in PAH; however, pericardial effusion occasionally reduces left ventricular transmural pressure enough to decrease cardiac output. Pericardiocentesis is usually not helpful [9] and can even be harmful, with a 50\% reported mortality [29]. It has been performed quite exceptionally in our centres.

\section{HAEMOPTYSIS}

According to the French national reference centre experience, haemoptysis is a rare complication in idiopathic and familial $\mathrm{PAH}$, as opposed to $\mathrm{PAH}$ associated with congenital heart disease, with 20 cases reported over a 10-yr period [30]. However, it can be life-threatening, with cumulative volumes averaging $79 \mathrm{~mL}$ (range $20-300 \mathrm{~mL}$ ) and survival rates of $60 \%$, $43 \%$ and $36 \%$ at 1,3 and 12 months, respectively. Bronchial artery embolisation is performed in $60 \%$ of the cases and recurrence is frequent $(75 \%)$ in both embolised and nonembolised patients. Hypertrophy of bronchial collateral arteries is the mechanism responsible for haemoptysis in $\mathrm{PAH}$ patients. Treatment does not differ from other causes of haemoptysis, for which there is no management consensus. Neutralisation of anticoagulation with vitamin K (10 mg orally) or protamine 
adapted to heparine dosage, administration of the antifibrinolytic tranexamic acid, bronchoscopy, airway protection with balloon tamponade or double lumen endotracheal tube, and selective embolisation are the usual steps.

\section{SURGERY}

Few studies have looked at the consequences of acute surgery in patients with PAH. Local peridural anaesthesia was not recommended because it decreases blood pressure by sympathetic block and decreased venous return. A high incidence of early postoperative morbidity and a mortality rate of $7 \%$ has been associated with noncardiac surgery in PAH patients [31] A recent paper by PRICE et al. [32] describes the outcome of procedures (16 abdominal, eight orthopaedic and four gynaecological; four in emergency; $50 \%$ under general anaesthesia) in 28 patients (36\% idiopathic, $36 \%$ associated $\mathrm{PAH}$ and $28 \%$ CTEPH; 75\% in NYHA class I-II). 29\% had PAH-related complications, with $7 \%$ deaths, four pulmonary hypertension crises, six severe hypotension and two severe hypoxaemia. Complication and death rates for the emergency procedures were $100 \%$ and $50 \%$, respectively. Risk factors for complications were emergency surgery $(p<0.001)$, major surgery $(\mathrm{p}=0.008)$ and long operative time (193 versus $112 \mathrm{~min} ; \mathrm{p}=$ 0.003). Another series from Kansas City, USA describes the results of 15 procedures performed in 14 patients with idiopathic and associated PAH [33]. Half of them were on i.v. epoprostenol. Anaesthesia was general in 93\%. A surprisingly low number of complications were reported: no deaths at 30 days, one patient with doubling of creatinine level and one with temporary oxygen therapy at home. The available data described above, however, do not allow set up of an ideal anaesthesia protocol for surgery in $\mathrm{PAH}$ patients, but suggest that local anaesthesia is safer than general anaesthesia. Peridural anaesthesia is also recommended by the European Society of Cardiologists/European Respiratory Society guidelines, as well as the temporary conversion to i.v. or inhaled treatment until patients are able both to swallow and to absorb drugs taken orally [5].

\section{DRUG-RELATED ADVERSE EVENTS}

PAH-specific therapy is generally well tolerated, but some side-effects can be serious and lead to hospitalisation and, sometimes, death. Liver toxicity, oedema and anaemia are frequently associated with the use of ERAs. Hyperthyroidism, thrombocytopenia, catheter infections and occlusions are reported with the use of PGI2 analogues.

The prevalence of liver toxicity decreases from bosentan (10$14 \%)$ to sitaxentan $(3-5 \%)$ to ambrisentan $(0.8-3 \%)$. It has been attributed to the inhibition of canalicular bile salt export and it is reversible after drug discontinuation [34]. Oedema is more frequent for ambrisentan and bosentan and is usually controlled by diuretics. Anaemia is modest and does not require treatment.

Hyperthyroidism can be aggravated by PGI2 therapy, but occurs mainly when given in association with amiodarone. It can be severe and cause persistent right heart failure. Treatment is based on thiamazolum $20 \mathrm{mg}$, propylthiouracil (PTU) $3 \times 100 \mathrm{mg}$ or steroids. PTU therapy has to be monitored cautiously as it can induce thrombocytopenia and liver toxicity. Digoxine is sometimes used to control tachycardia, as beta-blockers are contraindicated in PAH. Thrombocytopenia is frequent but does not require therapy as values remain above 50,000 platelets per $\mathrm{mL}$.

Catheter occlusion is a common event in patients treated with i.v. epoprostenol. Because of the short half life of epoprostenol, patients are instructed to undergo rapid insertion of a peripheral line for further drug infusion. Bloodstream infections have been reported in patients treated with both i.v. epoprostenol and treprostinil. According to a Centers for Disease Control and Prevention investigation conducted in 2003-2006 [35], a higher rate is observed with treprostinil (1.11 versus 0.43 per 1,000 medicine days; pooled incidence rate ratio 2.57). The three most common organisms isolated among patients on i.v. epoprostenol are coagulase-negative Staphylococcus, Micrococcus sp. and Staphylococcus aureus; among patients on i.v. treprostinil Pseudomonas sp., Enterobacter sp., and coagulase-negative Staphylococcus. More recently, the French national reference centre reported a high proportion of asymptomatic blood stream infection [36]. Patients had neither fever nor local signs of infection, but some had unexplained clinical deterioration, emphasising the importance of surveillance blood cultures. In this context, good clinical practice guidelines have been issued on the prevention and treatment of catheter infections [37].

\section{CASE REPORTS}

This last section aims to illustrate the precariousness of $\mathrm{PAH}$ patients in emergency situations.

The first patient is a 14-yr-old female with idiopathic $\mathrm{PAH}$, which had been treated with bosentan for 1 yr. She was in NYHA class II and 6-min walk distance (6MWD) was $540 \mathrm{~m}$. Tei index of right ventricular performance was 0.63 and tricuspid annular plane systolic excursion (TAPSE) $18 \mathrm{~mm}$. These indices all suggested a favourable outcome. She underwent a general anaesthesia for resection of an odontogenic keratocyst of the right mandibula at a large regional hospital. She was discharged the same day and died unattended at home on the same evening.

The second patient is a 41-yr-old female with portopulmonary hypertension who had been treated with sildenafil $(3 \times 20 \mathrm{mg})$ for 3 yrs. She was in NYHA class II, 6MWD was $525 \mathrm{~m}$, Tei index 0.74, TAPSE $24 \mathrm{~mm}$, and N-terminal pro-BNP $338 \mathrm{ng} \cdot \mathrm{L}^{-1}$. She had to undergo resection of a recurrent meningioma causing visual field defects. Sildenafil was preventively uptitrated to $3 \times 80 \mathrm{mg}$. As she was followed for the meningioma in another hospital than the PAH centre she decided to be operated on there. She died from perioperative cardiac arrest after $13 \mathrm{~h}$ of general anaesthesia.

Lesson 1: from these first two cases, we concluded that elective surgery should be performed at a PAH centre under the supervision of an experienced cardio-anaesthesiologist with access to all PAH therapies.

The third patient is a 72-yr-old female with drug-related PAH who had been treated with sitaxentan for 2.5 yrs. She was in NYHA class III, 6MWD was $405 \mathrm{~m}$, Tei index 1.28, and TAPSE $15 \mathrm{~mm}$. She had a locally advanced breast cancer for which neoadjuvant chemotherapy with taxanes was indicated, as we recommended against the use of cardiotoxic adriamycine. 
Sildenafil $3 \times 20 \mathrm{mg}$ was preventively added to the therapy. She died within 1 week as a consequence of electrolyte disturbances.

The fourth patient is a 60-yr-old female with drug-related PAH who had been treated with bosentan for 1.5 yrs. She was in NYHA class II, 6MWD was $370 \mathrm{~m}$, and Tei index 0.58. She experienced progressive shortness of breath for 1 week. The ECG performed at the regional hospital showed atrial fibrillation. As blood pressure was satisfactory, she was allowed to go home to get some clothes before transfer to our PAH centre for electrical cardioversion. She died unattended at home.

Lesson 2: from these two latter cases we learned not to underestimate the risks.

\section{CONCLUSION}

The emergency care of the unstable $\mathrm{PAH}$ patient requires immediate and close collaboration between critical care experts, anaesthesists and PAH experts. Whenever possible, these patients should be rapidly hospitalised in $\mathrm{PAH}$ reference centres. Most of the management of unstable PAH patients will be guided by clinical experience and pathophysiological reasoning. It is, indeed, unlikely that randomised controlled trials will be possible in unstable $\mathrm{PAH}$ patients to improve current treatment algorithms.

\section{STATEMENT OF INTEREST}

M. Delcroix has received fees for serving as investigator, speaker, consultant, or steering committee member from Actelion, Aventis Pharmaceuticals, Bayer, Eli Lilly, Encysive, Gilead (Myogen), GlaxoSmithKline, Nippon Shyniaku, Novartis, Pfizer, Schering, ?and United Therapeutics; educational grants from Actelion, GlaxoSmithKline, Pfizer, and Therabel; and research grants from Actelion, Encysive, Pfizer and GlaxoSmithKline. M. Delcroix is holder of the Actelion Chair for Pulmonary Hypertension and of the GSK Chair for Research and Education in Pulmonary Vascular Pathology at the Catholic University of Leuven. R. Naeije has served on advisory boards for Actelion, United Therapeutics, Mondobiotech and LungRX, and received speaker fees from Actelion, Pfizer, Bayer HealthCare, GSK and United Therapeutics, and research grants from Actelion and Pfizer.

\section{REFERENCES}

1 Simonneau G, Robbins IM, Beghetti M, et al. Updated clinical classification of pulmonary hypertension. J Am Coll Cardiol 2009; 54: S43-S54.

2 Humbert M, Sitbon O, Chaouat A, et al. Pulmonary arterial hypertension in France: results from a National Registry. Am J Respir Crit Care Med 2006; 173: 1023-1030.

3 Peacock AJ, Murphy NF, McMurray JJ, et al. An epidemiological study of pulmonary arterial hypertension. Eur Respir J 2007; 30: 104-109.

4 McLaughlin VV, Archer SL, Badesch DB, et al. ACCF/AHA 2009 expert consensus document on pulmonary hypertension a report of the American College of Cardiology Foundation Task Force on Expert Consensus Documents and the American Heart Association developed in collaboration with the American College of Chest Physicians; American Thoracic Society, Inc.; and the Pulmonary Hypertension Association. J Am Coll Cardiol 2009; 53: 1573-1619.

5 Galie N, Hoeper MM, Humbert M, et al. Guidelines for the diagnosis and treatment of pulmonary hypertension. The task force for the diagnosis and treatment of pulmonary hypertension of the European Society of Cardiology (ESC) and the European
Respiratory Society (ERS), endorsed by the International Society of Heart and Lung Transplantation (ISHLT). Eur Respir J 2009; 34: 1219-1263.

6 Hoeper MM, Galie N, Murali S, et al. Outcome after cardiopulmonary resuscitation in patients with pulmonary arterial hypertension. Am J Respir Crit Care Med 2002; 165: 341-344.

7 Sztrymf B, Souza R, Bertoletti L, et al. Prognostic factors of acute heart failure in patients with pulmonary arterial hypertension. Eur Respir J 2010; 35: 1286-1293.

8 Kurzyna M, Zylkowska J, Fijalkowska A, et al. Characteristics and prognosis of patients with decompensated right ventricular failure during the course of pulmonary hypertension. Kardiol Pol 2008; 66: 1033-1039.

9 Zamanian RT, Haddad F, Doyle RL, et al. Management strategies for patients with pulmonary hypertension in the intensive care unit. Crit Care Med 2007; 35: 2037-2050.

10 Naeije R, Vachiery JL. Medical therapy of pulmonary hypertension. Conventional therapies. Clin Chest Med 2001; 22: 517-527.

11 Liang KV, Williams AW, Greene EL, et al. Acute decompensated heart failure and the cardiorenal syndrome. Crit Care Med 2008; 36: S75-S88.

12 Mullens W, Abrahams Z, Francis GS, et al. Importance of venous congestion for worsening of renal function in advanced decompensated heart failure. J Am Coll Cardiol 2009; 53: 589-596.

13 Kerbaul F, Rondelet B, Motte S, et al. Effects of norepinephrine and dobutamine on pressure load-induced right ventricular failure. Crit Care Med 2004; 32: 1035-1040.

14 Deb B, Bradford K, Pearl RG. Additive effects of inhaled nitric oxide and intravenous milrinone in experimental pulmonary hypertension. Crit Care Med 2000; 28: 795-799.

15 Lobato EB, Beaver $\mathrm{T}$, Muehlschlegel J, et al. Treatment with phosphodiesterase inhibitors type III and V: milrinone and sildenafil is an effective combination during thromboxaneinduced acute pulmonary hypertension. Br J Anaesth 2006; 96: 317-322.

16 Rich S, Seidlitz M, Dodin E, et al. The short-term effects of digoxin in patients with right ventricular dysfunction from pulmonary hypertension. Chest 1998; 114: 787-792.

17 Kerbaul F, Rondelet B, Demester JP, et al. Effects of levosimendan versus dobutamine on pressure load-induced right ventricular failure. Crit Care Med 2006; 34: 2814-2819.

18 Kleber FX, Bollmann T, Borst MM, et al. Repetitive dosing of intravenous levosimendan improves pulmonary hemodynamics in patients with pulmonary hypertension: results of a pilot study. J Clin Pharmacol 2009; 49: 109-115.

19 Leather HA, Segers P, Berends N, et al. Effects of vasopressin on right ventricular function in an experimental model of acute pulmonary hypertension. Crit Care Med 2002; 30: 2548-2552.

20 Bhorade S, Christenson J, O'connor M, et al. Response to inhaled nitric oxide in patients with acute right heart syndrome. Am J Respir Crit Care Med 1999; 159: 571-579.

21 Christenson J, Lavoie $\mathrm{A}, \mathrm{O}^{\prime}$ connor $\mathrm{M}$, et al. The incidence and pathogenesis of cardiopulmonary deterioration after abrupt withdrawal of inhaled nitric oxide. Am J Respir Crit Care Med 2000; 161: 1443-1449.

22 Hoeper MM, Olschewski H, Ghofrani HA, et al. A comparison of the acute hemodynamic effects of inhaled nitric oxide and aerosolized iloprost in primary pulmonary hypertension. German PPH study group. J Am Coll Cardiol 2000; 35: 176-182.

23 Dantzker DR, D'Alonzo GE, Bower JS, et al. Pulmonary gas exchange during exercise in patients with chronic obliterative pulmonary hypertension. Am Rev Respir Dis 1984; 130: 412-416.

24 Achouh L, Montani D, Garcia G, et al. Pulmonary arterial hypertension masquerading as severe refractory asthma. Eur Respir J 2008; 32: 513-516.

25 Mekontso DA, Charron C, Devaquet J, et al. Impact of acute hypercapnia and augmented positive end-expiratory pressure on 
right ventricle function in severe acute respiratory distress syndrome. Intensive Care Med 2009; 35: 1850-1858.

26 Tongers J, Schwerdtfeger B, Klein G, et al. Incidence and clinical relevance of supraventricular tachyarrhythmias in pulmonary hypertension. Am Heart J 2007; 153: 127-132.

27 Goldstein JA, Harada A, Yagi Y, et al. Hemodynamic importance of systolic ventricular interaction, augmented right atrial contractility and atrioventricular synchrony in acute right ventricular dysfunction. J Am Coll Cardiol 1990; 16: 181-189.

28 Provencher S, Herve P, Jais X, et al. Deleterious effects of betablockers on exercise capacity and hemodynamics in patients with portopulmonary hypertension. Gastroenterology 2006; 130: 120-126.

29 Hemnes AR, Gaine SP, Wiener CM. Poor outcomes associated with drainage of pericardial effusions in patients with pulmonary arterial hypertension. South Med J 2008; 101: 490-494.

30 Jais X. Hemoptysis in pulmonary arterial hypertension (PAH): a life-threatening complication. Am J Respir Crit Care Med 2009; 179: A2667.

31 Ramakrishna G, Sprung J, Ravi BS, et al. Impact of pulmonary hypertension on the outcomes of noncardiac surgery: predictors of perioperative morbidity and mortality. J Am Coll Cardiol 2005; 45: 1691-1699.
32 Price LC, Montani D, Jais X, et al. Noncardiothoracic nonobstetric surgery in mild-moderate pulmonary hypertension. Eur Respir J 2010; 35: 1294-1302.

33 Lebourveau P, Williamson TL, Bartolome SD. Peri-operative management of pulmonary hypertension patients. Am J Respir Crit Care Med 2009; 179: A3344.

34 Fattinger K, Funk C, Pantze M, et al. The endothelin antagonist bosentan inhibits the canalicular bile salt export pump: a potential mechanism for hepatic adverse reactions. Clin Pharmacol Ther 2001; 69: 223-231.

35 Bloodstream infections among patients treated with intravenous epoprostenol or intravenous treprostinil for pulmonary arterial hypertension-seven sites, United States, 2003-2006. MMWR Morb Mortal Wkly Rep 2007; 56: 170-172.

36 O'Callaghan DS, Moutet A, Jais X, et al. Catheter related-infections in pulmonary hypertension patients treated by continuous intravenous epoprostenol: experience of the French referral centre. Am J Respir Crit Care Med 2010; 181: A3337.

37 Doran AK, Ivy DD, Barst RJ, et al. Guidelines for the prevention of central venous catheter-related blood stream infections with prostanoid therapy for pulmonary arterial hypertension. Int $J$ Clin Pract Suppl 2008; 5-9. 